\title{
Formation of large NAT particles and denitrification in polar stratosphere: possible role of cosmic rays and effect of solar activity
}

\author{
F. Yu \\ Atmospheric Sciences Research Center, State University of New York at Albany, Albany, New York, USA \\ Received: 16 December 2003 - Published in Atmos. Chem. Phys. Discuss.: 11 February 2004 \\ Revised: 1 June 2004 - Accepted: 19 July 2004 - Published: 23 November 2004
}

\begin{abstract}
The formation of large nitric acid trihydrate (NAT) particles has important implications for denitrification and ozone depletion. Existing theories have difficulty in explaining the formation of large NAT particles at temperatures above the ice frost point, which has been observed recently over wide Arctic regions. Our analyses reveal that highenergy comic ray particles might induce the freezing of supercooled $\mathrm{HNO}_{3}-\mathrm{H}_{2} \mathrm{O}-\mathrm{H}_{2} \mathrm{SO}_{4}$ droplets when they penetrate these thermodynamically unstable droplets. The cosmic rayinduced freezing (CRIF) appears to be consistent with the observed, highly selective formation of NAT particles. We suggest a possible physical process behind the CRIF mechanism: the reorientation of polar solution molecules into the crystalline configuration in the strong electrical fields of moving secondary ions generated by passing cosmic rays. A simple formula connecting the CRIF rate to cosmic ray flux is derived with an undefined parameter constrained by observed NAT formation rates. Our simulations indicate that strong solar proton events (SPEs) may significantly enhance the formation of large NAT particles and denitrification. The CRIF mechanism offers a possible explanation for the observed high correlations between the thin nitrate-rich layers in polar ice cores and major SPEs, and the observed enhancement in the aerosol backscattering ratio at PSC layers shortly after an SPE and the significant precipitation velocity of the enhanced PSC layers. The key uncertainty in the CRIF mechanism is the probability $(P)$ of freezing when a CR particle hits a thermodynamically, unstable STS droplet. Further studies are needed to either confirm or reject the CRIF hypothesis.
\end{abstract}

Correspondence to: $\mathrm{F}$. Yu

(yfq@asrc.cestm.albany.edu)

\section{Introduction}

Polar stratospheric clouds (PSCs) are crucial to the ozone depletion because of their well-recognized role both in activating chlorine (through heterogeneous reactions on the surface of PSC particles) and denitrifying the lower stratosphere (through gravitational settling of large $\mathrm{HNO}_{3}$-containing PSC particles) (e.g. Solomon, 1999; Word Meteorology Organization, 1999). During the recent SAGE III Ozone Loss and Validation Experiment (SOLVE), large nitric acid trihydrate (NAT) particles ("NAT rocks") at low number densities have been observed in a synoptic scale at temperatures above the frost point (Fahey et al., 2001). As a result of their significant fall speeds, these large NAT particles can lead to an irreversible removal of nitric acid which may prolong the lifetime of reactive chlorine and thereby enhance the ozone depletion. Climate models predict that the increased concentrations of greenhouse gases and the depletion of the ozone layer may lead to lower stratospheric temperatures and more widespread PSC formation and denitrification in the Northern Hemisphere (Shindell et al., 1998; Waibel et al., 1999). Modeling simulations show that widespread denitrification could enhance future Arctic ozone loss by up to $30 \%$ (Tabazadel et al., 2000). To evaluate properly the consequences of future lower stratospheric temperatures on the arctic ozone layer, details about the formation of large NAT particles must be known.

The large NAT particles observed in a synoptic scale at temperatures above the frost point (Fahey et al., 2001) are believed to be formed through the freezing of supercooled ternary solutions (STS) composed of $\mathrm{H}_{2} \mathrm{SO}_{4}, \mathrm{HNO}_{3}$ and $\mathrm{H}_{2} \mathrm{O}$. Since the observations indicate that only $\sim 0.002 \%$ $0.01 \%$ of these STS droplets froze, the freezing mechanism must be highly selective (Fahey et al., 2001; Tolbert and Toon, 2001). Currently, we have no satisfying theories to explain this "mysterious", highly selective freezing process observed during SOLVE (e.g. Fahey et al., 2001; Tolbert and Toon, 2001; Carslaw et al., 2002a; Jensen et al., 2002;

(C) 2004 Author(s). This work is licensed under a Creative Commons License. 
Drdla et al., 2003). Laboratory studies indicate that homogeneous freezing of STS particles are negligible at temperatures above the ice frost point under polar stratospheric conditions (Koop et al., 1995; Knopf et al., 2002). Homogeneous freezing on the particle surface may enhance the nucleation rate by a factor of $\sim 100$ (Tabazadeh et al., 2002), however, this enhancement is still too small to account for the observed production rate of large NAT particles. Since the large NAT particles were observed within a synoptic scale pool of air, the role of mountain waves in generating these particles (Carslaw et al., 1998) can also be excluded (Carslaw et al., 2002a). While laboratory experiments by Bogdan and Kulmala (1999) and Bogdan et al. (2003) suggested that silicas could trigger heterogeneous nucleation of nitric hydrates at temperatures above the ice frost point, these experiments were carried out for binary $\mathrm{HNO}_{3}-\mathrm{H}_{2} \mathrm{O}$ solutions which are different from the ternary $\mathrm{H}_{2} \mathrm{SO}_{4}-\mathrm{HNO}_{3}-\mathrm{H}_{2} \mathrm{O}$ solutions in the polar stratosphere. It is known to be much more difficult to initiate freezing in ternary $\mathrm{H}_{2} \mathrm{SO}_{4}-\mathrm{HNO}_{3}-\mathrm{H}_{2} \mathrm{O}$ solutions than in binary $\mathrm{HNO}_{3}-\mathrm{H}_{2} \mathrm{O}$ solutions. Biermann et al. (1996) tested the efficiency of meteoritic dust grains and a variety of other solid materials as nuclei in ternary $\mathrm{H}_{2} \mathrm{SO}_{4}-\mathrm{HNO}_{3}$ $\mathrm{H}_{2} \mathrm{O}$ solutions at temperatures as low as $188 \mathrm{~K}$ and detected negligible effects.

In this study, we explore the freezing of the supercooled ternary solutions (STS) as a result of the interactions between the thermodynamically unstable STS droplets and high-energy cosmic rays. The possible physics behind the cosmic ray-induced freezing (CRIF) is described. The CRIF mechanism is formulated and used in a 1-D polar stratospheric cloud (PSC) model to simulate the formation of PSC particles. The effect of solar activity on PSC properties and denitrification, and the observations supporting the CRIF mechanism are discussed.

\section{Cosmic ray-induced freezing (CRIF)}

Cosmic rays (CRs) entering the Earth's atmosphere are known to be able to initiate phase changes in supercooled vapor (e.g. Wilson, 1927) and superheated liquid (e.g. Glaser, 1960). The role of cosmic ray ionization in the formation of ultrafine particles in the atmospheric has received increasing interest in recent years (e.g. Yu and Turco, 2000; Yu, 2002; Carslaw et al., 2002b; Harrison and Carslaw, 2003, Lee et al., 2003). The possible enhancement in the freezing of supercooled water as a result of electrical interactions (i.e. electrofreezing) has been suggested in various studies (see textbook by Pruppacher and Klett, 1997; and review articles by Harrison and Carslaw, 2003; and Tinsley and Yu, 2004). The electrofreezing of supercooled water could be induced by (1) the direct passage of energetic particles, (2) strong electric fields, and (3) contact with ions.

Electrofreezing processes may also play a role in the formation of NAT particles in the polar stratosphere. It has been suggested earlier that the freezing of STS particles in the polar stratosphere may be initiated by the contact of the supercooled droplets with small ions or charged $\mathrm{HNO}_{3} / \mathrm{H}_{2} \mathrm{O}$ clusters (Hamil and Turco, 2000; Carslaw, 2001; D'Auria and Turco, 2001). The concentration of small ions in the polar stratosphere is around $10^{4} \mathrm{~cm}^{-3}$ and a typical STS droplet will collide with a small ion approximately every $10 \mathrm{~s}$. Thus, the ion contact freezing is unlikely to explain the observed high selective freezing, unless it is true that only certain very large charged clusters can initiate freezing (D'Auria and Turco, 2001). In this study we propose a possible freezing mechanism that is different from the earlier suggestion of ion-contact freezing (Hamil and Turco, 2000; Carslaw, 2001; D'Auria and Turco, 2001). All the molecules in the STS droplets $\left(\mathrm{HNO}_{3}, \mathrm{H}_{2} \mathrm{O}, \mathrm{H}_{2} \mathrm{SO}_{4}\right)$ have high dipole moments. For freezing, the dipoles need to be oriented and arranged into the crystalline configuration. Our proposed mechanism involves the reorientation of polar solution molecules into crystalline configuration in the strong electrical fields of moving secondary ions generated by the passing high-energy CRs.

When a primary CR particle (proton) hits a solution atom or molecule, secondary electrons are ejected in various directions with a spectrum of energies, and strong electric fields exist between the positive parent ion and ejected electrons. The strength of the electric fields $(E)$ between the positive ion and the ejected electrons, separated by $l \mathrm{~nm}$, can be approximated by:

$E(x)=\frac{e}{4 \pi \varepsilon_{0} \varepsilon_{r}}\left[\frac{q_{1}}{x^{2}}+\frac{q_{2}}{(l-x)^{2}}\right], 0<x<l$,

where $x$ is the position from a positive ion in the line connecting two ions; $\varepsilon_{0}$ is the vacuum permittivity, $\varepsilon_{r}$ is the relative permittivity of a liquid solution; $q_{1}$ and $q_{2}$ are the number of elementary charges $(e)$ carried by positive ion and negative ion (electron), respectively; $q_{1}=q_{2}=1$ for single ionization. For multiple ionization, $q_{1}>1$ and $q_{2}=1$, if the contribution of other electrons is ignored; $q_{2}$ could be $>1$ when electrons are ejected in same directions. Figure 1 shows the values of $E(x)$ corresponding to $q_{1}=1,4,8\left(q_{2}=1\right)$ and (a) $l=2 \mathrm{~nm}$, (b) $l=3 \mathrm{~nm}$. As an approximation, the relative permittivity for water $\left(\varepsilon_{r}=80\right)$ is used, since the value of $\varepsilon_{r}$ for STS is not available.

The electric fields between positive ion and electrons are sensitive to $l$ and $q_{1}$ (number of electrons ejected upon the collision of proton with atoms). In order to initiate freezing through the reorientation of solution molecules in the electrical fields of CR-generated positive ion and electrons, at least two conditions have to be met. First, the maximum separation between the parent ion and the ejected electrons has to be larger than the critical size of the crystalline embryo. The ejected energetic electrons will make inelastic collisions with liquid molecules and their kinetic energy will be transfered to these liquid molecules. The electrons will be neutralized by positive ion or absorbed by liquid molecules after a certain 
time. How far an electron can travel before being neutralized or absorbed depends on the initial velocity of the electron and hence the velocity or energy of incoming CR particles. The size of a critical embryo depends on the degree of supercooling and solution properties.

Second, the minimum strength of the electric field between the positive ion and electrons, separated by a distance of critical embryo size, should reach above a certain threshold value. Laboratory studies indicate that the electric fields have to be very large to cause the freezing of supercooled water droplets (e.g. Abbas and Latham, 1969; Braslavsky and Lipson, 1998). Analysis of both positive and negative experimental results relevant to the question of whether nucleation of ice is enhanced by the presence of an electric field indicates that electric fields on the order of $10^{8} \mathrm{~V} / \mathrm{m}$ might be essential in orienting polar molecules in a microscopic volume to initiate freezing (Tinsley and Deen, 1991). For $l=2$ $3 \mathrm{~nm}$ (typical sizes of a critical crystalline embryo), Fig. 1 indicates that multiple ionization is needed to reach electric fields of $10^{8} \mathrm{~V} / \mathrm{m}$. It is noteworthy that simultaneous electric fields and laminar flow have been found to be important in orienting crystalline embryos to initiate freezing (Pruppacher, 1963; Abbas and Latham, 1969; Doolittle and Vali, 1975; Tinsley and Deen, 1991; Pruppacher and Klett, 1997). Since the electrons are moving away from the positive parent ion at a certain speed, the polar molecules between the positive ion and the electron(s) experience simultaneous electric fields and laminar flow (relative to ions).

There is not much experimental study on the possible role of cosmic ray penetration in inducing the freezing of supercooled droplets. Varshneya (1969) observed tracks of ice crystal when CRs passed through the supercooled triple distilled, suspension free, pure water. Later, he developed a classical ion induced freezing theory which considers the contribution of electrostatic energy to the ice nucleation activation energy when the ice-like clusters are formed around ions (Varshneya, 1971). Tinsley and Deen (1991) showed clear correlations of winter cyclone intensity with day-to-day changes in the cosmic ray flux and suggested ice nucleation by passage of energetic CR particles as one of the possible mechanisms. Detwiler and Vonnegut (1980) and Seeley et al. (2001) tested the hypothesis about the ionization-induced freezing by irradiating supercooled water droplets with 5Mev alpha particles and found that the ionization of alpha particles has a negligible effect on water droplet freezing. Based on Varshneya's theory (1971), all ions generated by different sources should have a similar ability in initiating freezing. In this regard, Detwiler (1993) questioned the applicability of both Varshneya's experimental results and theory to ice nucleation in droplets in the upper tropospheric cloud. Nevertheless, Seeley et al. (2001) themselves pointed out that their measurement does not exclude the possibility that another type of energy range of cosmic rays induces ice nucleation.
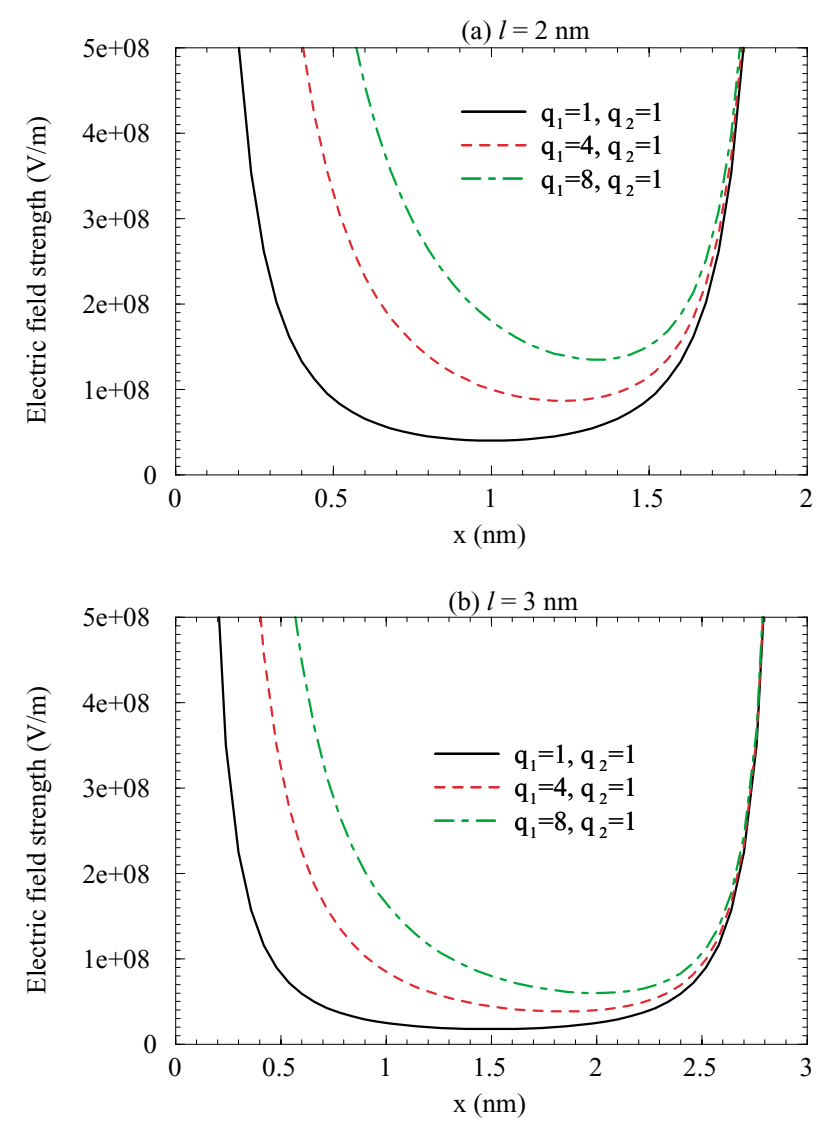

Fig. 1. The strength of electric fields at different positions in the line connecting positive parent ion and electrons. (a) $l=2 \mathrm{~nm}$, (b) $l=3 \mathrm{~nm} . q_{1}$ and $q_{2}$ are the number of elementary charge carried by positive ion and negative ion (electron), respectively.

In contrast to the ion-induced freezing as a result of the contribution of electrostatic energy to ice nucleation activation energy (as proposed by Varshneya, 1971), the physics behind our proposed CRIF is due to the reorientation of solution molecules into crystalline configuration in the strong electrical fields of moving secondary ions generated by passing cosmic rays. In order to initiate freezing, the energy of cosmic rays has to be above a certain level in order to cause certain multiple ionizations and to generate electrons that meet the two conditions listed above (i.e. electrons energetic enough to travel beyond the critical size and the electric fields between positive ion and electrons above a certain threshold value). For a critical crystalline embryo size of around 2-3 nm, Fig. 1 indicates that $q_{1}$ may have to be around 8 (a complete ionization of oxygen atom) to have an electric field above $10^{8} \mathrm{~V} / \mathrm{m}$. It is possible that the energy of alpha particles that Detwiler and Vonnegut (1980) and Seeley et al. (2001) used in their study is not high enough to initiate freezing under the conditions they investigated. Most of the CRs entering the polar stratosphere have energy larger than $100 \mathrm{Mev}$, with a significant fraction above $500 \mathrm{Mev}$. It is 
Table 1. Total ionization cross section $\sigma$ (from Dingfelder et al., 2000), mean free path $L$, probability of ionization for proton of different energies going through a liquid water droplet of different radius $r$.

\begin{tabular}{cccccc}
\hline Incident proton energy & $\sigma\left(\mathrm{m}^{2}\right)$ & $L(\mu \mathrm{m})$ & $P_{1}(r=0.1 \mu \mathrm{m})$ & $P_{1}(r=0.2 \mu \mathrm{m})$ & $P_{1}(r=0.3 \mu \mathrm{m})$ \\
\hline $5 \mathrm{Mev}$ & $3.4 \mathrm{E}-21$ & 0.009 & 1.0 & 1.0 & 1.0 \\
$50 \mathrm{Mev}$ & $5.0 \mathrm{E}-22$ & 0.061 & 0.85 & 0.96 & 0.98 \\
$200 \mathrm{Mev}$ & $1.8 \mathrm{E}-22$ & 0.168 & 0.53 & 0.76 & 0.86 \\
$500 \mathrm{Mev}$ & $1.1 \mathrm{E}-22$ & 0.275 & 0.37 & 0.60 & 0.73 \\
$1 \mathrm{Gev}$ & $8.8 \mathrm{E}-23$ & 0.344 & 0.31 & 0.52 & 0.66 \\
\hline
\end{tabular}

conceivable that the direct passage of these high-energy cosmic rays through the highly supercooled liquid may initiate freezing. Laboratory measurement using cosmic ray particles in the energy range common in the atmosphere is needed to test the CRIF theory proposed above. While such a measurement is currently unavailable, some observational phenomena appear to support the CRIF theory which we discuss below.

The CRIF production rate of solid NAT particles $\left(J_{N A T}^{C R I F}\right.$, in $\mathrm{cm}^{-3} \mathrm{sec}^{-1}$ ) from STS particles with number density $n$ $\left(\mathrm{cm}^{-3}\right)$ and radius $r$ can be estimated as,

$J_{N A T}^{C R I F}=n \pi r^{2} F_{C R} P$,

where $F_{C R}\left(\right.$ in $\mathrm{cm}^{-2} \mathrm{~s}^{-1}$ ) is the omni-directional flux of high energy CRs (protons). $P$ is the probability of freezing when a CR particle hits a supercooled STS droplet. $P$ can be expressed as,

$P=P_{1} * P_{2}$,

where $P_{1}$ represents the average chance that a CR particle going through the droplet has a collision with a solution atom, and $P_{2}$ represents the probability that freezing is initiated when the CR particle collides and ionizes the atom. Following the approach of Loeb (1939) in deriving the collision probability of an ion entering a sphere with an air molecule, we derive $P_{1}$ as,

$P_{1}=1-\frac{L^{2}}{2 r^{2}}\left[1-\left(\frac{2 r}{L}+1\right) e^{-\frac{2 r}{L}}\right]$,

where $L$ is the mean free path of CR particles (protons) in liquid solution and $r$ is the radius of a droplet. $L$ can be estimated as,

$L=\frac{1}{\sigma N}$,

where $\sigma$ is the proton ionization cross section and $N$ is the number of molecules per unit volume of liquid; $\sigma$ is a function of incident proton energy. We don't have information about the ionization cross section for protons in a ternary solution but we can use that of protons in liquid water as an approximation. Table 1 shows the values of $\sigma$ and $L$ for protons of different energies in liquid water and the corresponding values of $P_{1}$ with droplet radius of $r=0.1 \mu \mathrm{m}, 0.2 \mu \mathrm{m}$, and $0.3 \mu \mathrm{m}$. For STS droplets of typical sizes in the polar stratosphere $(\sim 0.2 \mu \mathrm{m}), P_{1}$ is likely to be above $\sim 0.5$.

$P_{2}$ depends on the detailed interaction of CRs (protons) with solution molecules/atoms (for example, the degree of ionization) and the critical size of a crystalline embryo. Thus, $P_{2}$ is likely to be a function of many parameters, including the energy of the incoming CRs, temperature, NAT supersaturation ratios $\left(S_{N A T}\right)$, composition and size of STS particles, and interfacial tension between the liquid and solid phases. The possible range of $P_{2}$ can be studied by looking into the multi-ionization cross section of cosmic rays of different energies and the behavior of polar molecules in the strong electric fields near the ions. However, just like the values of the activation energy used in the classical homogeneous freezing theory (Tabazadeh et al., 2000; Knopf et al., 2002), the values of $P_{2}$ may also have to be decided through laboratory studies and/or observations. Below we estimate the range of $P\left(=P_{1} * P_{2}\right)$ using the observed NAT production rates.

Figure 2 shows the dependence of $J_{N A T}^{C R I F}$ on the radius of STS particles at $P=0.01,0.1,1$. Typical CR flux in the polar stratosphere of $2.5 \mathrm{~cm}^{-2} \mathrm{~s}^{-1}$ and STS particle number concentration $(n)$ of $8 \mathrm{~cm}^{-3}$ are assumed. The observed NAT production rates shown in the figure are inferred from large mode (number density $\sim 2.3 \times 10^{-4} \mathrm{~cm}^{-3}$, mean diameter $\sim 14.5 \mu \mathrm{m}$ ) and small model (number density $\sim 2 \times 10^{-3} \mathrm{~cm}^{-3}$, mean diameter $\sim 3.5 \mu \mathrm{m}$ ) NAT particles observed by Fahey et al. (2001), assuming that these particles were accumulated in a $3( \pm 2)$-day period. The background sulfate aerosols generally have a mean radius of $\sim 0.07 \mu \mathrm{m}$ but can grow to a mean radius of $\sim 0.25 \mu \mathrm{m}$ by taking up $\mathrm{HNO}_{3}$ when $S_{N A T}>1$. Since the maximum radius of STS particles in typical stratospheric conditions is around $0.25 \mu \mathrm{m}$, we put the observed NAT production rates at the position of the $\mathrm{x}$-axis corresponding to a radius of $0.25 \mu \mathrm{m}$. In the real situations, freezing could happen on all sizes of STS particles as they grow from $\sim 0.07 \mu \mathrm{m}$ to $0.25 \mu \mathrm{m}$ by taking up $\mathrm{HNO}_{3}$. Figure 2 indicates clearly that CRIF rates have an upper limit of around $10^{-4} \mathrm{~cm}^{-3} \mathrm{~h}^{-1}(P=1)$ which is controlled by the chance that a CR particle hits a STS droplet. 
Thus, CRIF is highly selective, which meets the critique of nucleation mechanism inferred from observations (Fahey et al., 2001; Tolbert and Toon, 2001). Based on observed NAT production rates, $P$ should be in the range of 0.01 to 1 under the atmospheric conditions during the observations. The less than unity of the freezing probability can be understood as some CR particles may penetrate the STS droplets without inducing freezing because of various reasons, including (but not limited to): (1) low energy of the CRs, (2) low supersaturation of droplets, and (3) short CR path in the droplet (especially when CR penetrates the edge of the droplets).

\section{Simulations}

The CR-induced freezing rates (Eq. 2) depend on several variables (CR flux, particle concentration, particle radius); a PSC model with CRIF mechanism included can physically study the dependence of PSC properties on solar activity and other parameters (such as background aerosol concentrations, etc.). The key uncertainty in the proposed CRIF mechanism is the value of $P_{2}$ (or $P$ ) in Eq. (2). $P_{2}$ is estimated to be around 0.1, based on the Fahey et al. (2001) observation (see last section). To check if $P_{2}=0.1$ can reproduce the major features of PSC properties, we simulate PSC formation and denitrification with CRIF as the freezing mechanism. The simulation presented in this section also serves as the baseline case for studying the effect of SPEs on denitrification (next section).

We use a one-dimensional (1-D) PSC model from the Denish Meteorogical Institute (DMI) (Larsen, 2000; Larsen et al., 2002). The DMI PSC model calculates the time dependent PSC particle size distributions and chemical compositions, together with changes in gas phase mixing ratios of water vapor $\left(\mathrm{H}_{2} \mathrm{O}\right)$ and nitric acid vapor $\left(\mathrm{HNO}_{3}\right)$. The formation (nucleation), growth, evaporation, and sedimentation of various types of PSC particles are simulated in the model with up-to-date thermodynamic data.

The initial profile and sinusoidal oscillation of temperature and the initial nitric acid mixing ratio profile follow those of Jensen et al. (2002). The temperature oscillation is an idealized representation of the temperature variations experienced by air mass circulating around the pole during the winter of 2000 when SOLVE measurements were made. The initial altitude $(h)$ dependent temperature $\left(T_{0}(h)\right)$ has a minimum of $197 \mathrm{~K}$ at $h=20 \mathrm{~km}$, and increases linearly to $202 \mathrm{~K}$ at $30 \mathrm{~km}$ and to $217 \mathrm{~K}$ at $10 \mathrm{~km}$. The temperatures at all altitudes follow a sinusoidal evolution as $T(h)=T_{0}(h)+4.5 \times\{\sin [2 \pi(1 / 4+t / \tau)]-1\}$, where $\tau$ is the oscillation period. The temperature profile and oscillation amplitude were based on the early to mid-January Arctic conditions (Newmann and Harries, 2002). We follow Jensen et al. (2002), using $\tau=6$ days as the baseline case and include $\tau=12$ days in the sensitivity study. The $\mathrm{HNO}_{3}$ gas mixing ratio has a maximum value of $9 \mathrm{ppbv}$ at $20 \mathrm{~km}$, with the mix-

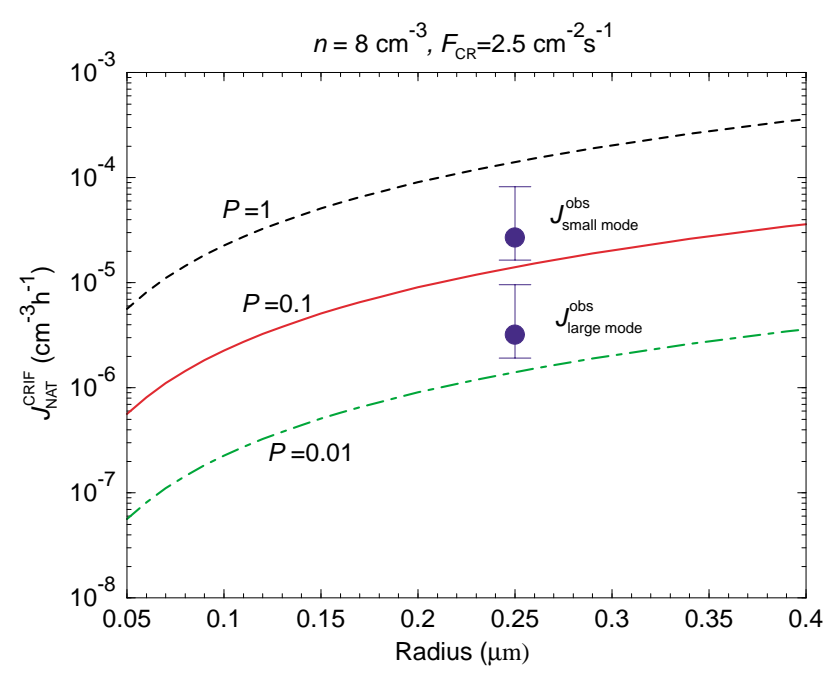

Fig. 2. Cosmic ray-induced freezing (CRIF) production rate of solid NAT particles $\left(J_{N A T}^{C R I F}\right)$ as a function of the radius of STS droplets at three different values of $P(0.01,0.1,1) . P$ is the probability of freezing when a cosmic ray particle hits a supercooled STS droplet, which is likely to be a function of many parameters (see text for details). The observed NAT production rates shown are inferred from large mode and small model NAT particles measured by Fahey et al. (2001), assuming that these particles were accumulated in a 3( \pm 2$)$-day period. The error bars indicate the possible ranges of freezing rate if the observed NAT particles are assumed to be accumulated in a period of 1-5 days.

ing ratio decreasing below this altitude down to about $2 \mathrm{ppbv}$ in the lowermost stratosphere, which is typical of the polar stratosphere in early winter (Gille et al., 1996). A water mixing ratio of $5 \mathrm{ppmv}$ is assumed. The initial background sulfate aerosol is from Deshler et al. (2003). At the $20 \mathrm{~km}$, the total number concentration, median radius, standard deviation for mode 1 and mode 2 are $7.67 \mathrm{~cm}^{-3}, 0.069 \mu \mathrm{m}, 1.63$ and $0.006 \mathrm{~cm}^{-3}, 0.42 \mu \mathrm{m}, 1.11$, respectively. The same mixing ratio of sulfate is assumed at other altitudes. The vertical space resolution is $200 \mathrm{~m}$. The cosmic flux $\left(F_{C R}\right)$ profile, corresponding to the 2000 winter polar stratosphere, is interpolated based on the balloon measurements of cosmic ray fluxes in February 1987 (maximum fluxes) and November 1989 (minimum fluxes) in polar latitudes (Bazilevskaya and Svirzhevskaya, 1998) and cosmic ray intensities measured with the Climax Neutron Monitor.

The temperature oscillation is an idealized representation of the temperature variations experienced by air mass circulating around the pole during the winter of 2000 when SOLVE measurements were made. As discussed earlier, $P$ depends on $S_{N A T}$ and other parameters, and the dependence relation remains to be investigated. As a first approximation, we assume $P=0.1$ and that the freezing becomes possible only when $S_{N A T}$ is larger than 10 (Jensen et al., 2002) in this study. While the details of simulated PSC properties will 
vary when different values of $P$ are used, the main features of the results and conclusion will not change.

Figure 3 presents the model results plotted versus time and altitude: (a) temperature, (b) $S_{N A T}$, (c) $\mathrm{HNO}_{3}$ gas mixing ratio, (d) CR-induced freezing rate $\left(J_{N A T}\right)$, (e) total number concentration of NAT particles, (f) median diameter of NAT particles. The temperature reaches the lowest value at $t=3$ days and $S_{N A T}$ can reach up to 30 . The classical homogenous freezing theory predicts negligible $\left(<10^{-8} \mathrm{~cm}^{-3} \mathrm{~h}^{-1}\right)$ nucleation under the condition that the activation energy at the similar $S_{N A T}$ derived from recent laboratory data (Knopf et al., 2002) is used. With $P=0.1$, the CR induced freezing rate can reach up to $3.5 \times 10^{-5} \mathrm{~cm}^{-3} \mathrm{~h}^{-1}$ (Fig. 3d). The concentrations of NAT particles reach above $10^{-4} \mathrm{~cm}^{-3}$ between $17 \mathrm{~km}$ and $21 \mathrm{~km}$, with a maximum concentration of $\sim 10^{-3} \mathrm{~cm}^{-3}$ at $20 \mathrm{~km}$ (Fig. 3e). The median diameters of NAT particles are in the range of $8-13 \mu \mathrm{m}$ in the area where significant NAT particles are present (concentration $>10^{-4} \mathrm{~cm}^{-3}$ ) (Fig. 3f). The simulated size and concentration of NAT particles are qualitatively consistent with the measurements of Fahey et al. (2001), with the understanding that the temperature history and vertical structures of the air mass where the observations were made are more complex than those assumed in our simulation. There are some denitrification at altitudes between 19.5 and $22 \mathrm{~km}$ and some renitrification between $16 \mathrm{~km}$ and $19.5 \mathrm{~km}$ (Fig. 3c). The depth of NAT saturated layer limits the sedimentation of NAT particles, as NAT particles sublimate when $S_{N A T}<1$. A longer PSC duration time will increase the sizes of NAT particles and enhance the denitrification (Jensen et al., 2002, also see next section).

The main properties of PSC shown in Fig. 3 are similar to that presented in Jensen et al. (2002). This is not surprising since the initial profile and sinusoidal oscillation of temperature and the initial nitric acid mixing ratio profile used in this study are the same as those of Jensen et al. (2002). The major difference between our study and the Jensen et al. (2002) simulation is that we use Eq. (2) to calculate the cosmic ray-induced freezing while Jensen et al. (2002) used a constant freezing rate to represent an unidentified freezing mechanism. With the CRIF mechanism included in the model, we can investigate how solar activity may affect PSC properties and denitrification.

\section{Effect of solar activity on PSC properties and denitri- fication}

It is known that solar activities affect $F_{C R}$ in polar stratosphere significantly. $F_{C R}$ at altitudes between $15-25 \mathrm{~km}$ in the polar stratosphere almost doubles from solar maximum to solar minimum during the regular 11-year solar cycle, and strong solar proton events (SPEs) can increase the CR fluxes in polar stratosphere by a factor of $\sim 10-30$. Figure 4 shows the balloon-based measurements of $F_{C R}$ as a function of al- titude in northern polar regions (Murmansk, cut-off rigidity $=600 \mathrm{Mev}$ ) under different conditions of solar activities. The data for $F_{C R}$ during solar minimum (February 1987, $F_{C R}$ maximum), during solar maximum (November 1989, $F_{C R}$ minimum), and during the strongest solar proton event in October 1989 are from Bazilevskaya and Svirzhevskaya (1998). The $F_{C R}$ profile corresponding to the 2000 winter polar stratosphere (used for calculations presented in Fig. 3) is interpolated based on $F_{C R}$ maximum and minimum profiles and the CR intensities measured with the Climax Neutron Monitor. It is noteworthy that CRs have the maximum flux in the polar stratosphere where PSCs form.

CRIF is very selective (less than $0.1 \%$ of particles with a radius of $0.2 \mu \mathrm{m}$ will be hit by CRs during a 3-day period) and the freezing rate is proportional to $F_{C R}$ (Eq. 2). Thus, we should expect to see the enhanced production rate of large NAT particles and hence denitrification when CR fluxes increase. Using representative $F_{C R}$ profiles during four different solar activities (maximum, minimum, and average solar activities, and during strong SPEs; Fig. 4) and with temperature oscillation periods $(\tau)$ of 6 days and 12 days, we compare the corresponding $\mathrm{HNO}_{3}$ mixing ratio profiles at $t=\tau$ (Fig. 5). Significant denitrification and renitrification at different altitudes are obvious and the extended life of PSC significantly enhances the denitrification. From the solar maximum $\left(F_{C R}\right.$ minimum) to solar minimum $\left(F_{C R}\right.$ maximum), the denitrification at altitudes between $20-22 \mathrm{~km}$ increases by up to $0.6 \mathrm{ppbv}$ (7\%) for $\tau=6$ days (3.5-day cloud lifetime) and up to $1.3 \mathrm{ppbv}$ (15\%) for $\tau=12$ days (7-day cloud lifetime).

The strong SPEs significantly enhance the denitrification, especially in the top layer of PSCs. The renitrification layer during SPEs also shifts to lower altitudes. Thus, compared to non-SPE periods, SPEs lead to extra denitrification in the cloud top layer of around $2 \mathrm{~km}$ depth and move the renitrification layer by $1 \mathrm{~km}$. For the temperature assumed in this study, NAT particles are not able to reach the surface due to sublimation. However, a significant amount of nitric acid has been moved downward by up to $\sim 5 \mathrm{~km}$ for $\tau=6$ days and by up to $\sim 8 \mathrm{~km}$ for $\tau=12$ days. This downward-moved nitric acid can precipitate to the ground in subsequent cloud and precipitation processes. As a result, the enhanced denitrification during the SPEs might have a signal in the nitric acid deposited in polar ice cores.

Actually, the thin nitrate-rich layers in both Arctic and Antarctic firn and ice cores have been found to be highly positively correlated with periods of major solar proton events (the probability of chance correlation less than $10^{-9}$ ) (McCracken et al., 2001). Most importantly, the impulsive events in the nitrate record are all short-lived (many have a time constant of 2 weeks, none has one greater than 6 weeks) (McCracken et al., 2001). Solar proton events are known to increase $\mathrm{NO}_{\mathrm{x}}$ concentration in the mesosphere and upper stratosphere (e.g. Jackman et al., 2001). However, it has been estimated (Dunkerton, 1978) that the downward 

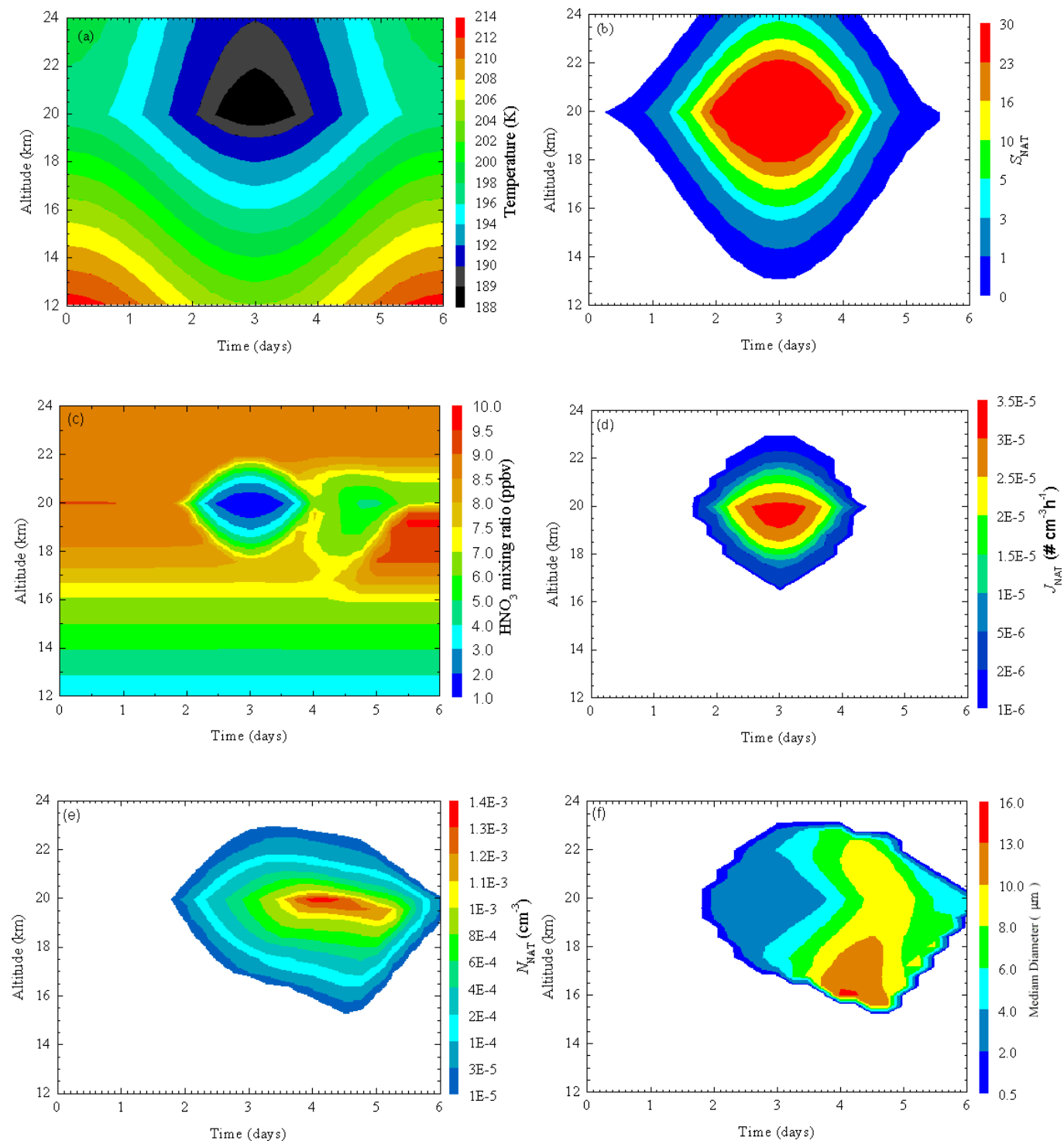

Fig. 3. PSC simulation using a 1-D PSC model with the cosmic ray-induced freezing mechanism included. Fields are plotted versus time and altitude: (a) temperature (K), (b) $S_{N A T}$, (c) $\mathrm{HNO}_{3}$ gas mixing ratio (ppbv), (d) NAT particle production rate $\left(\mathrm{cm}^{-3} \mathrm{~h}^{-1}\right),(\mathbf{e})$ total number concentration of NAT particles $\left(\mathrm{cm}^{-3}\right)$, (f) median diameter of NAT particles $(\mu \mathrm{m})$. The initial profile and sinusoidal oscillation of temperature follow those of Jensen et al. (2002), which is an idealized representation of the temperature variations experienced by air mass circulating around the pole during the winter of 2000 when SOLVE measurements were made. The lowest temperature is above the ice frost point and classical homogenous freezing theory predicts negligible nucleation. The cosmic ray-induced freezing can qualitatively explain the highly selective formation of NAT particles observed during SOLVE (Fahey et al., 2001).

transport of $\mathrm{HNO}_{3}$ in the gaseous phase from mesosphere and upper stratosphere to the troposphere would take at least 3-6 months. McCracken et al. (2001) concluded that the time scale of the nitrate events is too short to be understood in terms of transport mechanisms in the gaseous phase, and suggested that PSC formation processes and the nitrate precipitation might be enhanced during and after major SPEs (which is consistent with CRIF mechanism). Thus, the high correlations between the nitrate-rich layers in polar ice cores and major solar proton events (McCracken et al., 2001) might support the CRIF mechanism.

Shumilov et al. (1996) reported a considerable increase in the aerosol backscatter ratio after a strong SPE. Analysis of meteorological data indicates that the increase was not associated with temperature change and seems to be caused by the SPE (Shumilov et al., 1996). The mechanism Shumilov et al. (1996) offered to explain that the aerosol backscatter ratio enhancement is the increase in aerosol concentration as 


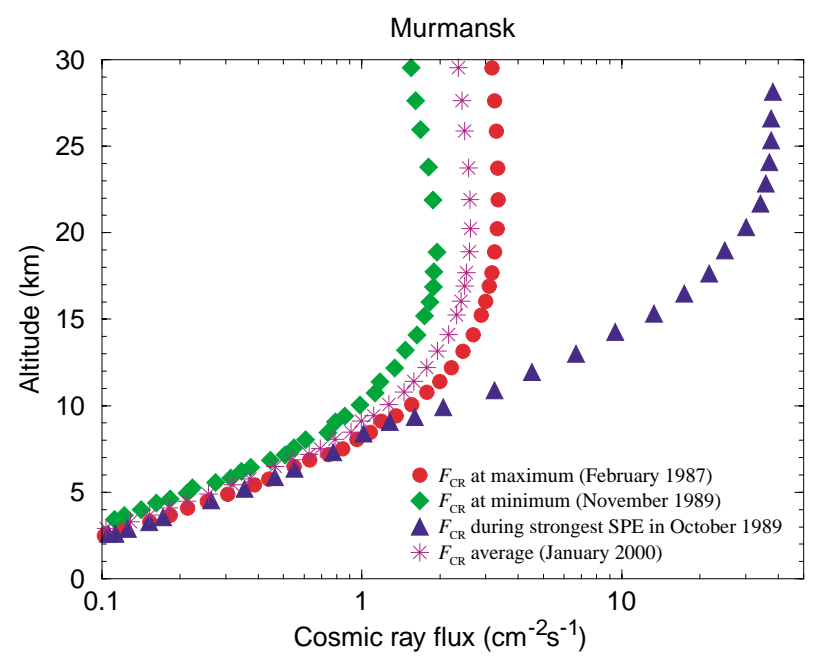

Fig. 4. Balloon-based measurements of $F_{C R}$ as a function of altitude in northern polar regions (Murmansk, cutoff rigidity=600 Mev) under different conditions of solar activities. The data for $F_{C R}$ during solar minimum (February 1987, $F_{C R}$ maximum), during solar maximum (November 1989, $F_{C R}$ minimum), and during the strongest solar proton event in October $1989\left(F_{C R}\right.$ SPE) are from Bazilevskaya and Svirzhevskaya (1998). The $F_{C R}$ profile corresponding to the 2000 winter polar stratosphere $\left(F_{C R}\right.$ average; used for calculations presented in Fig. 3) is interpolated based on $F_{C R}$ maximum and minimum profiles and the cosmic ray intensities measured with the Climax Neutron Monitor.

a result of SPE-induced enhancement in the ion nucleation rate of ultrafine particles. This explanation is questionable because the concentration of sulfuric acid gas in winter polar stratosphere is extremely low $\left(<\sim 10^{5} \mathrm{~cm}^{-3}\right)$ and the increase in ionization rate may not lead to an increase in the formation of fresh ultrafine particles (Yu, 2002). It also takes a long time to grow the fresh nucleated sulfuric acid particles to a size that can be detected by lidar (radius $>0.69 \mu \mathrm{m}$ ). Furthermore, the profiles of the aerosol backscattering ratio indicates that the enhanced particle layer formed precipitated quickly (1-2 km/day). Only PSC particles of around $10 \mu \mathrm{m}$ can have this precipitation velocity. To form PSC particles of around $10 \mu \mathrm{m}$, the freezing process must be very selective (Fahey et al., 2001). The considerable increase in the aerosol backscatter ratio after a strong SPE and the fast precipitation velocity of the enhanced particle layer are actually consistent with the CRIF mechanism.

CRIF process appears to provide a direct and more convincing explanation for the high correlation between the thin nitrate-rich layers in polar ice cores and major SPEs (McCracken et al., 2001) and the observed enhancement in aerosol backscattering ratio at PSC layers shortly after the SPE (Shumilov et al., 1996).

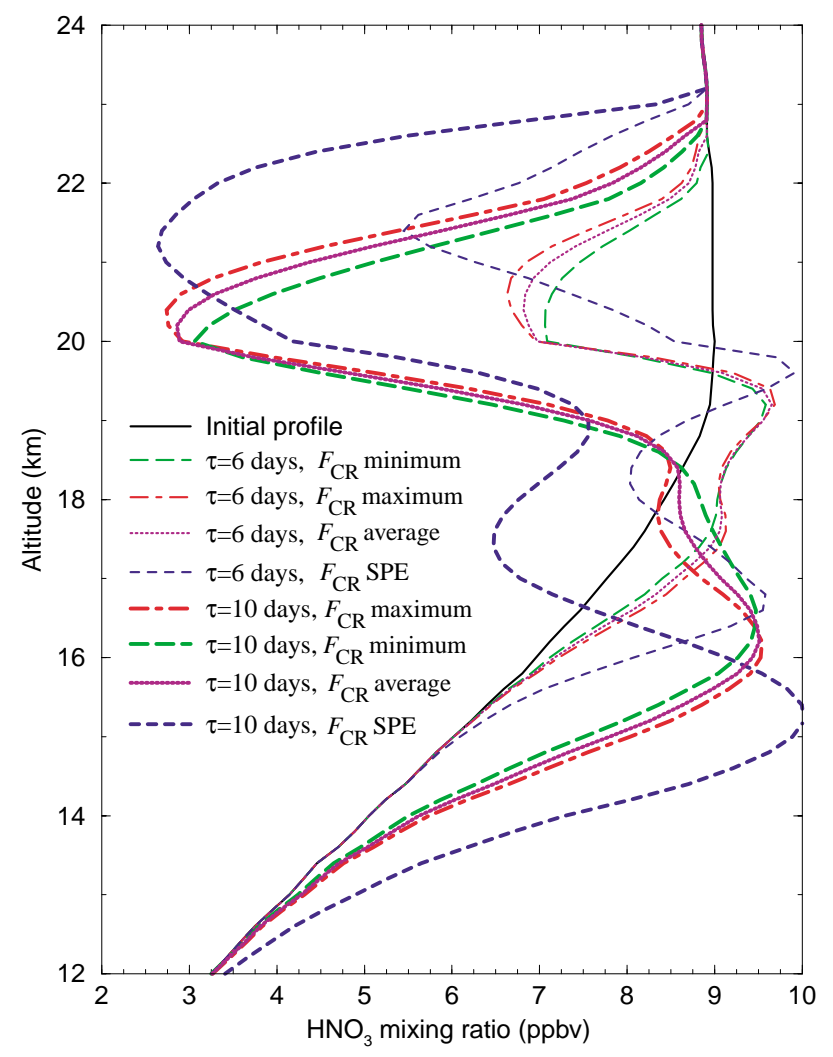

Fig. 5. Simulated $\mathrm{HNO}_{3}$ mixing ratio profiles at $t=\tau$ using representative $F_{C R}$ profiles corresponding to four different solar activities (maximum, minimum, and average solar activities, and during strong SPEs; Fig. 4) and with temperature oscillation periods $(\tau)$ of 6 days and 12 days. The initial $\mathrm{HNO}_{3}$ profile is also shown for comparison. The strong SPEs significantly enhance the denitrification, especially in the top layer of PSCs. The renitrification layer during SPEs also shifts to lower altitudes. The cosmic ray-induced freezing may explain the high correlation between the impulsive nitrate events in polar ice cores with major PSCs and the existence of such correlations provides strong, indirect support for the CRIF mechanism.

\section{Summary and discussion}

The existing theories on nitric acid trihydrate (NAT) particle formation can't explain the formation of large NAT particles observed recently over wide regions in the Arctic vortex. We propose that high energy comic ray particles might induce the freezing of the supercooled $\mathrm{HNO}_{3}-\mathrm{H}_{2} \mathrm{O}-\mathrm{H}_{2} \mathrm{SO}_{4}$ droplets when they hit and penetrate these droplets in the polar stratosphere. The mechanism of CR-induced freezing (CRIF) may involve the reorientation of polar solution molecules into crystalline configuration in the strong electrical fields of moving secondary ions generated by passing CRs, which is different from the earlier suggested ioninduced freezing theory considering the contribution of electrostatic energy to ice nucleation activation energy. In order 
to initiate freezing, the energy of cosmic rays may have to be above a certain level. Only high energy CRs can induce certain multiple ionizations and generate electrons so that the electrons are energetic enough to travel beyond the critical size, and the electric fields between positive ions (carry multiple charges) and electrons are above certain threshold values. The CRIF mechanism is highly selective, which is consistent with the formation of a few large nitric acid trihydrate (NAT) particles ("NAT rocks") observed during SOLVE (Fahey et al., 2001).

The CRIF mechanism is formulated and included in a 1-D polar stratospheric cloud (PSC) model to simulate the formation and properties of type 1 PSCs and the associated denitrification. The key uncertainty in the CRIF mechanism is the probability $(P)$ of freezing when a CR particle hits a thermodynamically unstable STS droplet. The measurements of Fahey et al. (2001) are used to constrain the values of $P$. Our simulations indicate that strong solar proton events (SPEs) may significantly enhance the formation of large NAT particles and denitrification. The CRIF process appears to offer a reasonable explanation for the observed enhancement in the aerosol backscattering ratio at PSC layers shortly after the SPE and the high correlations between the thin nitrate-rich layers in polar ice cores and major SPEs.

The idea of the possible role of cosmic rays in STS freezing is not new but the earlier suggestions focus on the ioncontact freezing process (Hamill and Turco, 2000; Carslaw, 2001; D'Auria and Turco, 2001). Our proposed CRIF mechanism focuses on a different physical process which involves the direct interaction of high energy CRs with STS droplets and might naturally explain the highly selective formation of NAT particles in the polar stratosphere. The CRIF mechanism, if confirmed, may shed new light on the effect of solar activities on the NAT particle formation, denitrification, and ozone depletion, and may provide a theoretical foundation to use nitrate events in polar ice cores to infer past SPEs and solar activities. The CRIF could also contribute to the highly selective freezing of supercooled water droplets in the upper troposphere which might have important climatic implications.

Since the probability $(P)$ of freezing when a CR particle hits a STS droplet is not defined, the CRIF mechanism is far from established. Further studies are clearly needed to either confirm or reject the CRIF hypothesis. A laboratory study using cosmic ray particles in the energy range common in the atmosphere is needed to test the CRIF theory. Since CR particles in the energy range common in the atmosphere can not be generated in a regular laboratory, the practical approach is to observe whether freezing occurs when natural CR particles penetrate STS droplets. Techniques to detect the incoming CRs need to be developed to confirm the penetration of STS droplets by CRs. It is interesting to note that, in their laboratory measurements studying homogeneous freezing of supercooled solutions, Koop et al. (1995) and Beyer et al. (1994) found that, for the same conditions, usually a subgroup of the sample froze in a very short time, while the rest took very long or did not freeze at all. While Koop at al. (1995) have attributed such freezing to the formation of ice frost or NAT on the containment walls from the vapor phase, such spontaneous freezing could also be due to the cosmic ray-induced freezing. Note that the flux of CRs in a laboratory room is likely to be very small $\left(<\sim 0.005 \mathrm{~cm}^{-2} \mathrm{~s}^{-1}\right)$, thus only a very limited number of droplets is likely to be hit by CRs in the laboratory at a given time period. Observations of PSC particle changes during and after strong SPEs may provide useful information on CRIF. Theoretical investigation of how protons interaction with solution molecules/atoms and how polar molecules in solution react to the strong electric fields are also necessary.

Acknowledgements. This work was supported by the NSF under grant ATM 0104966. We thank N. Larsen for the DMI PSC model used in this study.

Edited by: K. Carslaw

\section{References}

Abbas, M. A. and Latham, J.: The electrofreezing of supercooled water droplets, J. Meteorol. Soc. Jpn., 47, 65, 1969.

Bazilevskaya, G. A. and Svirzhevskaya, A. K.: On the stratospheric measurements of cosmic rays, Space Sci. Rev., 85, 431-521, 1998.

Beyer, K. D., Seago, S. W., Chang, H. Y., and Molina, M. J.: Composition and freezing of aqueous $\mathrm{H}_{2} \mathrm{SO}_{4} / \mathrm{H}_{2} \mathrm{O}$ solutions under polar stratospheric conditions, Geophys. Res. Lett., 21, 871, 1994.

Biermann, U. M., Presper, T., Koop, T., et al.: The unsuitability of meteoritic and other nuclei for polar stratospheric cloud freezing, Geophys. Res. Lett., 23, 1693-1696, 1996.

Bogdan, A. and Kulmala, M.: Aerosol silica as a possible candidate for the heterogeneous formation of nitric acid hydrates in the stratosphere, Geophys. Res. Lett., 26, 1433-1436, 1999.

Bogdan, A., Molina, M. J., Kulmala, M., MacKenzie, A. R., and Laaksonen, A.: Study of finely divided aqueous systems as an aid to understanding the formation mechanism of polar stratospheric clouds: Case of $\mathrm{HNO}_{3} / \mathrm{H}_{2} \mathrm{O}$ and $\mathrm{H}_{2} \mathrm{SO}_{4} / \mathrm{H}_{2} \mathrm{O}$ systems, J. Geophys. Res., 108 (D10), 4302, doi:10.1029/2002JD002605, 2003.

Braslavsky, I. and Lipson, S. G.: Electrofreezing effect and nucleation of ice crystals in free growth experiments, Appl. Phys. Lett., 72, 264-266, 1998.

Carslaw, K. S., Wirth, M., Tsias, A., et al.: Particle microphysics and chemistry in remotely observed mountain polar stratospheric clouds, J. Geophys. Res., 103, 5785-5796, 1998.

Carslaw, K. S., Kettleborough, J. A., Northway, M. J., et al.: A vortex-scale simulation of the growth and sedimentation of large nitric acid hydrate particles, J. Geophys. Res., 107 (D20), 8300, doi:10.1029/2001JD000467, 2002a.

Carslaw, K. S., Harrison, R. G., and Kirkby, J.: Cosmic Rays, Clouds, and Climate, Science, 298, 1732-1737, 2002b.

Carslaw, K.: Cosmic rays - a missing link also in the stratosphere? Transparencies presented at the Ion-Aerosol-Cloud In- 
teractions Workshop, CERN, April 18-20, http://cloudws.web. cern.ch/cloudws/transparencies.html, 2001.

D'Auria, R. and Turco, R. P.: Ionic clusters in the polar winter stratosphere, Geophys. Res. Lett., 28 , 3871-3874, 2001.

Deshler, T., Hervig, M. E., Hofmann, D. J., Rosen, J. M., and Liley, J. B.: Thirty years of in situ stratospheric aerosol size distribution measurements from Laramie, Wyoming $\left(41^{\circ} \mathrm{N}\right)$, using balloon-borne instruments, J. Geophys. Res., 108, 4167, doi:10.1029/2002JD002514, 2003.

Detwiler, A. and Vonnegut, B.: Initiation of freezing in supercooled cloud droplets by ionizing radiation, J. Atmos. Sci., 37, 479-480, 1980.

Detwiler, A.: Comment on "Apparent tropospheric response to $\mathrm{MeV}-\mathrm{GeV}$ particle flux variations: A connection via electrofreezing of supercooled water in high-level clouds?", J. Geophys. Res., 98, 16 887-16888, 1993.

Dingfelder, M., Inokuti, M., and Paretzke, H. G.: Inelastic-collision cross sections of liquid water for interactions of energetic protons, Radiat. Phys. Chem., 59, 255-275, 2000.

Doolittle, J. B. and Vali, G.: Heterogeneous freezing nucleation in electrical fields, J. Atmos. Sci., 32, 375-379, 1975.

Drdla, K., Schoeberl, M. R., and Browell, E. V.: Microphysical modeling of the 1999/2000 Arctic winter, 1, Polar stratospheric clouds, dentrification, and dehydration, J. Geophys. Res., 108, 8312, doi:10.1029/2001JD000782, 2003.

Dunkerton, T.: On the mean meridional mass motions of the stratosphere and mesosphere, J. Atmos. Sci., 35, 2325-2333, 1978.

Fahey, D. W., Gao, R. S., Carslaw, K. S., et al.: The detection of large $\mathrm{HNO}_{3}$ particles in the winter Arctic stratosphere, Science, 291, 1026-1031, 2001.

Gille, J. C., Bailey, P. L., and Craig, C. A.: Revised reference model for nitric acid, Adv. Space Res., 18, 125-138, 1996.

Glaser, D. A.: Elementary particles and bubble chamber, Noble Lecture, December 12, 1960.

Hamill, P. and Turco, R. P.: Ion nucleation of NAT in ternary system polar stratospheric clouds, Trans. Amer. Geophys. Union, 81 (\#19, 9 May 2000) Suppl., S97, 2000.

Harrison, R. G. and Carslaw, K. S.: Ion-aerosol-cloud processes in the lower atmosphere, Rev. Geophys., 41 (3), 1012, doi:10.1029/2002RG000114, 2003.

Jackman, C. H., McPeters, R. D., Labow, G. J., et al. : Northern Hemisphere atmospheric effects due to the July 2000 solar proton event, Geophys. Res. Lett., 28, 15, 2883-2886, 2001.

Jensen, E. J., Toon, O. B., Tabazadeh, A., and Drdla, K.: Impact of polar stratospheric cloud particle composition, number density, and lifetime on denitrification, J. Geophys. Res., 107 (D20), 8284, doi:10.1029/2001JD000440, 2002.

Knopf, D. A., Koop, T., Luo, B. P., Weers, U. G., and Peter, T.: Homogeneous nucleation of NAD and NAT in liquid stratospheric aerosols: Insufficient to explain denitrification, Atmos. Chem. Phys., 2, 207-214, 2002,

SRef-ID: 1680-7324/acp/2002-2-207.

Koop, T., Biermann, U. M., Raber, W., Luo, B. P., Crutzen, P. J., and Peter, T.: Do stratospheric aerosol droplets freeze above the ice frost point?, Geophys. Res. Lett., 22, 917-921, 1995.

Larsen, N., Høyer Svendsen, S., Knudsen, B. M., et al.: Microphysical mesoscale simulations of polar stratospheric cloud formation constrained by in situ measurements of chemical and optical cloud properties, J. Geophys. Res., 107 (D20), 8301,
doi:10.1029/2001JD000999, 2002.

Larsen, N.: Polar stratospheric clouds: Microphysical and optical models, Sci. Rep. 00-06, Dan. Meteorol. Inst., Copenhagen, 2000.

Lee, S.-H., Reeves, J. M., Wilson, J. C., et al.: Particle Formation by Ion Nucleation in the Upper Troposphere and Lower Stratosphere, Science, 301, 1886-1889, 2003.

Loeb, L. B.: Fundamental processes of electrical discharge in gases, John Willey and Sons, Inc., New York, 1939.

McCracken, K. G., Dreschhoff, G. A. M., Zeller, E. J., Smart, D. F., and Shea, M. A.: Solar cosmic ray events for the period 15611994, 1, Identification in polar ice, 1561-1950, J. Geophys. Res., 106, A10, 21 585-21 598, 2001.

Newman, P. A., Harris, N. R. P., Adriani, A., et al.: An overview of the SOLVE-THESEO 2000 campaign, J. Geophys. Res., 107 (D20), 8259, doi:10.1029/2001JD001303, 2002.

Pruppacher, H. R. and Klett, J. D.: Microphysics of Clouds and Precipitation, 2nd ed., Kluwer Acad., Norwell, Mass., 1997.

Pruppacher, H. R.: The effect of an external electric field on the supercooling of water drops, J. Geophys. Res., 68, 4463-4467, 1963.

Seeley, L. H., Seidler, G. T., Dash, J. G.: Laboratory investigation of possible ice nucleation by ionizing radiation in pure water at tropospheric temperatures, J. Geophy. Res., 106, 3033-3036, 2001.

Shindell, D. T., Rind, D., and Lonergan, P.: Increased polar stratospheric ozone losses and delayed eventual recovery owing to increasing greenhouse-gas concentrations, Nature, 392, 589-592, 1998.

Shumilov, O. I., Kasatkina, E. A., Henriksen, K., and Vashenyuk, E. V.: Enhancement of stratospheric aerosols after solar proton event, Ann. Geophys., 14, 1119-1123 1996.

Solomon, S.: Stratospheric ozone depletion: A review of concepts and history, Rev. Geophys., 37, 275-316, 1999.

Tabazadeh, A., Santee, M. L., Danilin, M. Y., Pumphrey, H. C., Newman, P. A., Hamill, P. J., and Mergenthaler, J. L.: Quantifying denitrification and its effect on ozone recovery, Science, 288, 1407-1411, 2000.

Tabazadeh, A., Djikaev, Y. S., Hamill, P., and Reiss, H.: Laboratory Evidence for Surface Nucleation of Solid Polar Stratospheric Cloud Particles, J. Phys. Chem. A., 106, 10 238-10 246, 2002.

Tinsley, B. A. and Deen, G. W.: Apparent tropospheric response to Mev-Gev particle flux variations: A connection via electrofreezing of supercooled water in high-level clouds, J. Geophys. Res., 96, 22 283-22 296, 1991.

Tinsley, B. A. and Yu, F.: Effects of particle flux variations on clouds and climate, in: Solar Variability and its Effect on Climate, edited by: Pap, J. M. and Fox, P., Geophysical Monograph Series, Vol. 141, 2004.

Tolbert, M. A. and Toon, B.: Atmospheric science - Solving the PSC mystery, Science, 292, 61-63, 2001.

Varshneya, N. C.: Detecting radiation with a supercooled liquid, Nature, 223, 826-827, 1969.

Varshneya, N. C.: Theory of radiation detection through supercooled liquid, Nucl. Instrum. Meth., 92, 147-150, 1971.

Waibel, A. E., Peter, Th., Carslaw, K. S., Oelhaf, H., Wetzel, G., Crutzen, P. J., Pöschl, U., Tsias, A., Reimer, E., and Fischer, H.: Arctic ozone loss due to denitrification, Science, 283, 20642069, 1999. 
Wilson, C. R.: On the cloud method of making visible ions and the tracks of ionizing particles, Noble Lecture, 12 December 1927.

World Meteorological Organization (WMO): Scientific Assessment of Ozone Depletion, 1998, Rep. 44, Global Ozone Res. and Monit. Proj., Geneva, 1999.
Yu, F.: Altitude variations of cosmic ray induced production of aerosols: Implications for global cloudiness and climate, J. Geophy. Res., 107 (A7), 10.1029/2001JA000248, 2002.

Yu, F. and Turco, R. P.: Ultrafine aerosol formation via ionmediated nucleation, Geophys. Res. Lett., 27, 883-886, 2000. 